\title{
Risk allocation in public private partnerships in China's water projects: a principal agent approach
}

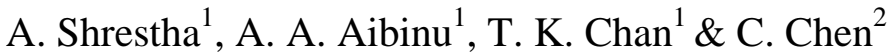 \\ ${ }^{1}$ Faculty of Architecture, Building and Planning, \\ The University of Melbourne, Australia \\ ${ }^{2}$ The Business School, Sichuan University, China
}

\begin{abstract}
Past research on China's public private partnerships (PPPs) shows that due to local governments' lack of understanding, risks are not allocated properly. Long term contracts in the water sector present its own risks, unique due to the characteristic of water projects; however, there is little or no research about risk allocation on these projects in the literature. Risk and their allocation in PPP water projects are regarded as any other PPP project and are not analysed independently. Most research regarding risks in PPP projects in China have been done from the private sectors' perspective and very limited research have focused on the government's point of view. In this paper, we develop a framework to examine risk allocation particularly for PPP water projects from the government's perspective in the context of China. Based on a review of the literature on risk allocation, three criteria were identified and used for the development of the framework and these criteria were discussed using the principal agent (PA) theory approach.
\end{abstract}

Keywords: water projects, public private partnerships, risk allocation, China.

\section{Introduction}

Water shortage is the single most tangible problem leading to low quality of life for millions of people around the world. There is goodwill amongst government officials to alleviate this burden but often their efforts are undermined by the lack of capability and other constraints to find optimal answers. With the problems of 
insufficient resources and public funds to facilitate the provision of services in China's water sector, the Public Private Partnership (PPP) has progressed as an alternative model for project procurement and delivery in China. However, PPP still remain a relatively new topic for many local governments and they lack the expertise and knowledge regarding risk allocation in PPPs which has led to several PPP water project to undergo lengthy delays, re-negotiations and sometimes even cancellations [1]. Due to the complex nature as well as its lengthy duration, PPPs are susceptible to a broader range of risks compared to traditional procurement methods [2]. So managing risks efficiently is one of the most important factors leading to a successful PPP project [3-5]. Even though China is one of the most active countries in terms of adopting PPPs in the water sector, no set of rules or framework exist for risk allocation in PPP projects [6].

Risks in water projects are important to manage as the water market can be a sensitive topic for governments. Moreover, water sector is different due to its unique characteristics and its importance to human life. Hanemann [7] provides two crucial features of water: its mobility and its variability. He describes that water is always mobile making it difficult to track and variable in terms of space, time and quality which means that it is unevenly distributed and even within the same location, its attributes may change over time. And it is due to these characters, the water sector faces risks that are different to other sectors. Furthermore, the water sector has a monopolistic nature where; the most common form of exploitation can be firms raising the price above marginal cost without the fear of losing its customers [8]. This in turn can lead to inefficiency as there may be little incentive for private firms to implement cost saving strategies. Though, in China's case the government has a strong influence over water pricing and the private sector may not have capacity to exploit monopoly rents (directly from the people), however, when the private sector has stronger bargaining power and when the government is ill informed, they can extract rents (from the government) in the form of subsidies or guarantees. While, the government may seek to minimize the price of water for the people, providing too much subsidies and guarantees may result in excessive costs on taxpayers as well as reduced risk transfer to the private sector.

There have been a growing number of studies related to the risks in PPPs in China [9-12], however most of these studies have been done from the private sectors' perspective and very limited research have focused on the government's point of view. In addition, most studies have regarded PPP 'water' projects as any other PPP project and risks and their allocation in PPP water projects have rarely been analysed independently.

In this paper, we develop a theoretical framework to examine risk allocation particularly for PPP water projects from the government's perspective in the context of China. Looking at risk allocation from the public sector perspective is important not only because governments are key stakeholders in PPP projects, but more importantly, it is their responsibility to make sure projects are successful in terms of achieving benefits for the people in the long run. Investigating in this area, can not only fill the gap in the literature but also work 
as a practical starting point for governments and private sectors in negotiating risk allocation in PPP water projects in the future.

\section{Defining 'success' of PPPs}

Risk allocation is vital in a successful PPP project, but what does success mean? For a project to be successful there should be goals that it needs to meet. Goals are sometimes met and sometimes not. If goals are met the project can be successful. Goals are sometimes missed by certain margins that are acceptable; however, when the outcome deviates from the expected goals to an unacceptable margin, the project can be unsuccessful. For goals to be met in a project, risks have to be managed and for risks to be managed they have to be allocated efficiently.

In general terms, project completion can be an indication of success. An uncompleted or abandoned project may be regarded as an unsuccessful project. Many PPP water projects in China and around the world have failed due to one (or both) party exiting from the partnership. For instance, the project company, which is normally referred to as the special purpose vehicle (SPV), may exit the partnership if the expected return on investment cannot be realised and the government may exit by cancelling the PPP and taking over the project if the service standard are not achieved. Negotiation between the government and the private sector is common, especially due to the long term nature of PPPs; nonetheless major negotiations (re-negotiations) of PPP contracts can be a big threat for the success of PPPs. Guasch et al. [13] find that the social costs of renegotiations are high in the water sector. From the perspective of transaction costs, re-negotiations can add to the costs for the project which could cause it from deviating from the (acceptable) targets levels. In addition, the private sector can have more bargaining power during re-negotiations allowing them to impose more guarantees (payments) from governments in their favour.

Though there are several aspects of PPPs that motivate both parties towards similar goals, it is important to note that what government see as success and what the private sector see as success in a PPP contract may not be the same. Therefore achieving the balance between government and private sector in regards to the levels of success that both parties have achieved (or want to achieve) can be a good measure of success in a PPP. This concept is common in literature and is normally termed as win- win [14]. However, achieving the winwin balance is difficult due to the existence of risks. Risk is normally understood as an undesirable event that can cause project outcomes to be worse than planned [15]. Additionally, it is the very conflicting 'meaning of success' for different parties that causes problems in achieving the win-win balance. Figure 1 illustrates how the win-win balance can be achieved through risk allocation amidst risks and agency problems. A shown in figure 1, both the government and the private sector will be tempted towards increasing their own goals or utility levels but that can lead to risks to the project that affect the win- win balance. Therefore, it is the government's responsibility, as a principal to manage difficulties created by agency problems through proper allocation of risks. 


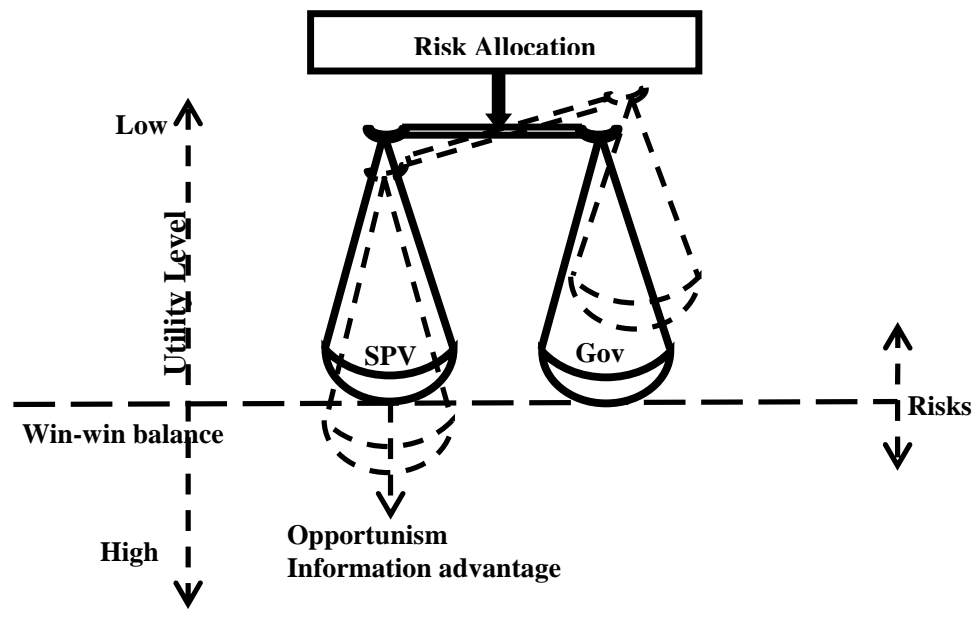

Figure 1: Win-win balance with the proper risk allocation. (Note: Gov = Government, SPV = Special Purpose Vehicle.)

According to Shirley and Menard [16], PPPs are likely to be successful when these three conditions are met: (i) credible signs of commitment from both parties, (ii) reduced information asymmetry between parties and (iii) incentives are provided to the operator to comply with contract goals. Keeping these conditions in mind, we develop a theoretical framework for risk allocation using the principal agent approach.

\section{Developing a theoretical framework}

In the context of risk allocation in PPP projects, several studies have examined how risks should be allocated $[17,18]$. However, from the broad literature in risk management, two main criteria emerge:

(i) risk should be allocated to the party best able to manage it

(ii) risk should be allocated to the party who can bear the risk at the lowest cost

These risk allocation criteria have evolved mainly from the notions of law and economics and have been adopted by many countries for allocating risks in a PPP projects as well. These criteria are primarily based on the Abrahamson's [19] work where he looked at efficiency of risk allocation in construction projects and identified five criteria. Based on his principles, a certain risk should be allocated to the party when:

(i) the risk is within their control

(ii) they can transfer this risk in an economically beneficial way

(iii) the economic benefit of the risk rests with that party

(iv) it is more efficient to put the risk on that party

(v) if the risk eventuates, the loss falls on that party and there is no valid reason to try to transfer it. 
These principles suggest that the party to whom the risk is allocated should have the control over the risk, should have the ability to be efficient in managing the risk, and finally, should have the incentive to manage the risk. In addition to Abrahamson's work, Posner and Rosenfield [20] set the framework for the analysis of efficient risk allocation by looking at it from a legal/contractual perspective where they defined the 'superior risk bearer' as the party who is in the best position to bear the risks. According to them, the superior risk bearer is better at:

(i) minimising the probability of the risk,

(ii) minimising the extent of the loss either before or after it occurs;

(iii) insuring (by self or with third parties) against the residual risk of the loss that cannot be feasibly avoided.

The concept of the superior risk bearer was developed further by Triantis [21] who go on to explain how one party can be a superior risk bearer when he has more information regarding the risk. What information means here is the parties' ability to understand or assess the probability and the severity of risks.

Based on the discussed literature, three important criteria are identified for the allocating risks, i.e. (i) control, (ii) information and (iii) incentive. These three criteria can form the basis or examining who the risk should be allocated to. Below, the three criteria are discussed one at a time.

\subsection{Control over the risk}

Generally, having control over the risks means having the ability to manage the risks efficiently, however to do so, it is important to consider various aspects of risks. For example, some risks are exogenous where parties may not have direct control over it and some risks may be endogenous, meaning the party (or parties) has some level of control over the risks. Control also has two meanings: it could mean preventing it from occurring or controlling it after it has occurred. In deciding who has control over the risk, several factors need to be taken into account. First of all, if the risk is exogenous, it has to be considered which party has better ability to bear the consequences if the risk materialises. It also has to be considered which party has the better mitigation measures. If the risk is endogenous, it has to be taken into account, which party is more capable in preventing the risk from occurring or which party in more capable in reducing the severity of the risk.

Here, the superior risk bearer criteria [20] sets out a clearer definition in regards to who can control the risk more efficiently as exogenous and endogenous risks are considered both before it has occurred and after. Therefore, this can be a good way of determining the party who has more control over the risk.

While endogenous risks can be allocated based on analysing who has more control over the risk in terms of influence over the probability, it should also be assessed if the risk bearing party bears the risk at a lowest cost. This concerns their ability to transfer the risk to a third party or retain the risk. Allocation of exogenous risks on the other hand, can be more complex as both parties do not have the direct influence over the risk. So in this case, it has to be assessed how 
the risk bearer will confront the risks if they materialise, i.e. either find ways to reduce its impact or transfer it to a third party or retain the risk. Furthermore, the more important question is if the risk bearer will charge a high premium for bearing the risk. Employing the Arrow Lind Theorem, it has been argued that the government should be responsible for bearing exogenous risks as they have a better ability to diversify the risks among tax payers, in the case the risk materialises. Portfolio theory also applies to investment in public infrastructure projects where it is argued that government have larger portfolio of projects, therefore can bear the risk at a lower cost. However, private sector can be equally capable in terms of spreading risk as large companies also have a significant number of shareholders and can bear risk cheaply [15]. Therefore, choosing the right SPV in terms of size and portfolio can be an important factor in determining their risk bearing capacity.

\subsection{Information regarding the risk}

The risk management process is characterised by 3 stages: identification, assessment and mitigation [22]. The ultimate purpose of the identification and assessment stages is to prepare to mitigate or control the risks during the project. However, to be able to identify and assess risks, it is essential to have information regarding risks. Information here means understanding the risks in terms of their chances of occurrence together with the consequence if it occurs. This information helps in evaluating risks during the assessment stage where critical risks are identified.

To be able to control risks or to know if the party can control risk, it has to be assessed which party has that information. If the party does not have the right (amount of) information regarding risks, then their assessment of risks can be inaccurate. Hence, the more robust the information, the better the chances are of reliable risk assessments. Therefore, it may be crucial for the risk bearer to be superior in terms of information they possess regarding risks [21].

Obtaining information is very important, though sometimes it may be expensive. Sometimes information may be unavailable while other times it may be available but the risk bearer may not have the ability to understand it. Ting et al. [23] found that that information asymmetry and uncertainty due to task complexity are major causes of agent opportunism. Sometimes, the information may lie with the private sector and for opportunistic reasons; they may not want to share it. Information is also at the core of agency problems. Managing information by the principal is necessary to prevent problems with adverse selection as well as moral hazard, both of which can be considered risks and at the same time, can also lead to other risks. The government while selecting SPV will need reliable information regarding potential agents to avoid PA problems and make sure completion for the contract should remain robust. In fact, Muller and Turner [24] found that opportunism can be reduced with the degree of competition for contracts; the higher the competition, the lower the chances for opportunistic behaviour from agents.

One way of managing ex post information is to integrate vertically [25]. Though the ownership is transferred to the private sector in PPPs, governments 
as regulators can have some control in terms of overseeing the project. However, direct control, involves costs to the government. As the agents are selected for their specialized knowledge, vertical integration in PPPs requires the government to have a high level of expertise in terms of monitoring technical aspects of the project. In addition, vertical integration may also involve monitoring the level of efforts the private sector puts in to achieve efficiency. However, monitoring all aspects of project by the governments can be expensive and impractical; hence the costs may outweigh the benefits of PPPs. Sometimes efforts of the agents cannot be monitored or assessed. It can be due to the lack of (or wrong) information provided by the agent or it could be due to high technicality of the information and obtaining the (right) information could be too costly for the principal. In this situation, instead of monitoring the effort levels of the agent, the government can measure the performance by looking at the final results or outcomes [26]. Most PPP contracts are generally based on an output specification approach where the standards of services are set by the government whereas how that standard is going to be achieved depends on the SPV. This is more applicable in the water sector where a standard is set up in terms of threshold values of water quality and quantity which will be monitored and measured by the government or a third party. The private sector not being able to meet these standards can result in being penalised meaning the risk for not meeting the project goals in terms of the threshold values is transferred to the SPV. For the purpose of controlling and monitoring the private sector party, these standards should be clearly defined, measurable in quantitative and qualitative terms, and verifiable by third parties [27].

Therefore risk allocation in contracts should focus on allocating risk to the party with better information. Moreover, contracts should also enforce information sharing mechanisms between parties with the aim of allowing stronger control over agent opportunism and information asymmetry.

\subsection{Incentive to manage the risk}

Incentives in PPPs could mean penalties, subsidies, guarantees or sharing of risks. In most PPP water projects in China, the ownership is transferred to the private sector that not only finances but also constructs, operates and maintains the project for long duration of time. Such bundling of activities is believed to provide the private sector with an in-built incentive mechanism to be efficient [28]. This mechanism also creates opportunities of risk transfer from the public to the private sectors. However, it doesn't mean that they will perform in the way the principal wants. The private sector may not have the incentive to manage all the risks they are allocated and this can cause moral hazard where the private company can use information asymmetry to hide their opportunistic actions. Therefore a direct incentive which focuses on reducing the problems related to information asymmetry and moral hazard can be introduced in the contract. Tirole [8] stresses, one way to get around agency problems is to offer a fixed price contract but with an option to partly move towards cost-plus type contracts. According to the incentives theory proposed by Laffont and Martimort [29], it is suggested that incentive-based contracts can be used to motivate agents in PPPs. 
By providing the optimum level of incentives the government can ensure that their own goals are achieved. The stronger the incentives, the less needs there will be for monitoring. And sometimes monitoring and incentives need to be combined with each other together inducing the agent to comply with the contractual terms so that the PA problems can be avoided. Incentive based contracts in PPPs may consist of cost sharing and price sharing arrangements together with set of penalties or incentive payments. In addition, performance bonds and insurance arrangements can be included.

However for governments, attracting the interest of the private sector is quite important when considering projects using the PPPs models in the initiation phase. And when the governments are more desperate for private funds, they may have to attract potential bidders using some incentives that can offer opportunities to the private companies to generate a good return by promising to provide them with some form of guarantees or rewards. This means some (components of) risks are borne by the government or shared to a certain degree. However, Klein [30] indicates that though it may be wise to share some of the risks in order to attract the private sector, it may also raise the possibility of moral hazard.

Though the transfer of risks to the private sector is one of the key elements of successful PPPs, when it comes to some risks of high magnitudes, it is likely that the private sector may not agree to bear them. Even if they bear the risks, they may charge a premium which is most likely to be high. Sometimes exogenous risks that were not anticipated when the contract was signed, may occur and if these risks were not induced by either the government or the private sector this could be problematic as both parties will not be willing to accept the responsibility of managing the risk. In these situations, opportunism during (re) negotiations may be common from the private sector which, in turn may affect the efficiency as well as the overall welfare desired from the project.

"Risk and incentives go together" [31, p. 27] as the party who bears the risk will have the incentive to minimize its impact while the other may have no incentive to manage the risk even when the risk is under their control and this may give rise to the moral hazard problem. Hölmstrom [32] developed a contract which characterized the trade-off of risk sharing and effort distortion between a risk neutral principal and a risk adverse agent. They discuss that, in order to motivate the agent, the principal has to expose him to some levels of risk.

However, in some cases the anticipated risks may not occur at all, but the risk adverse agent may still charge a high premium for bearing the risk. Therefore, "it is better for the owner to pay for what does happen rather than for what the contractor thought might happen in those areas of doubt over which the contractor has no influence” [31, p. 27]. Sharing some risks, but only to a certain degree, by the government can not only solve this problem but also give the private sectors incentive to bear the risk knowing that anything unexpected that has a major effect on their revenue can draw subsidies from the government. Risk sharing can be done by both parties sharing the costs of the risks in an agreed proportion, if it materialises; sometime even symmetrical. This type of 
allocation provides an incentive to both parties to reduce the likelihood or consequences of the risk [33].

\section{The framework for risk allocation}

A preliminary framework for the allocation of risks has been developed using the three criteria discussed and is shown in figure 2. For every important risk, using

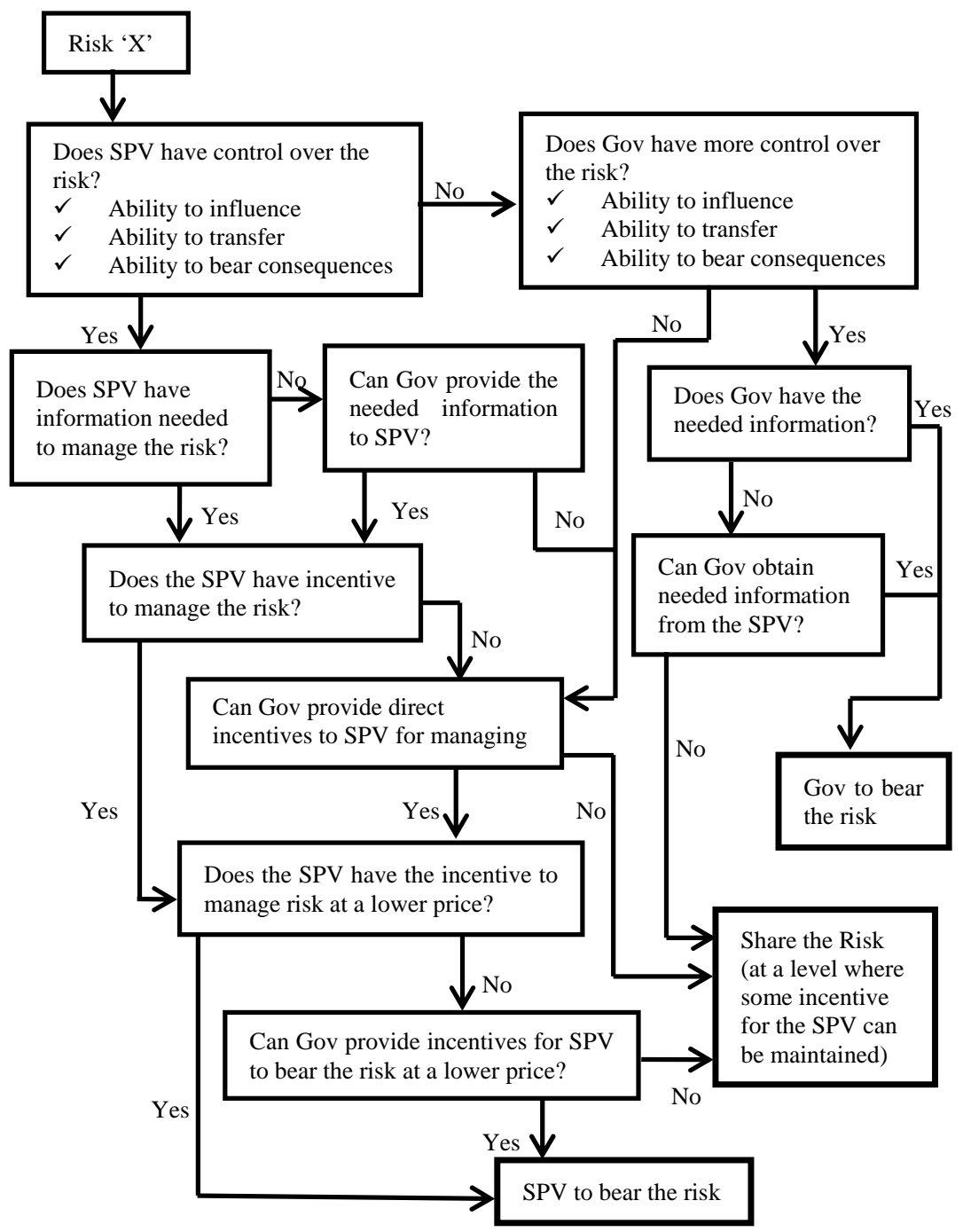

Figure 2: The risk allocation framework. (Note: Gov = Government, $\mathrm{SPV}=$ Special Purpose Vehicle.) 
the framework, it can be assessed how it should be allocated. Firstly, the SPV and the government is assessed for their ability to control the risk in terms the ability to influence the risk, the ability to transfer risk to third parties and the ability to bear the consequences of the risk if it materialises. It is then considered if the information is available (and if it can be made available) for the parties to manage the risk as well as avoid information asymmetry. Finally it is evaluated if the incentives to manage the risks are provided so that moral hazard can be avoided. Based on these assessments, risks can be allocated either to the SPV or to the government sector or shared.

\section{Conclusion}

This paper developed a framework for the allocation of risk for public private partnership (PPP) water projects. This proposed framework, presents as guide for conducting further research on the allocation of risks from the perspective of the governments in China. A suggested approach would be to: (i) identify all major risks in PPP water projects and; (ii) based on the proposed framework, identify how risks should be allocated. The final framework could be used as a practical guide for local governments and the special purpose vehicles (SPVs) during negotiations for risk allocation in PPP water projects in China. Further research would test the integrity of the theoretical framework presented as well as further shed light on strategies the public sector in China can adopted for the allocation of risks in PPP water projects.

\section{References}

[1] Wang, S. Q., Lessons learnt from the PPP practices in China (keynote speech). Asian Infrastructure Congress, Hong Kong, pp. 29-30, 2006.

[2] Grimsey, D., and Lewis, M. K., Evaluating the risks of public private partnerships for infrastructure projects. International Journal of Project Management, 20(2), pp. 107-118, 2002.

[3] Abdel Aziz, A. M., Successful Delivery of Public-Private Partnerships for Infrastructure Development. Journal of Construction Engineering \& Management, 133(12), pp. 918-931, 2007.

[4] Ke, Y., Wang, S., Chan, A. P. C., and Lam, P. T. I., Preferred risk allocation in China's public-private partnership (PPP) projects. International Journal of Project Management, 28(5), pp. 482-492, 2010.

[5] Li, B., Akintoye, A., and Hardcastle, C., Critical success factors for PPP/PFI projects in the UK construction industry. Construction management and economics, 23(5), pp. 459-471, 2005.

[6] Sachs, T., Tiong, R., and Wang, S. Q., Analysis of political risks and opportunities in public private partnerships (PPP) in China and selected Asian countries: Survey results. Chinese Management Studies, 1(2), pp. 126-148, 2007.

[7] Hanemann, W. M. The economic conception of water. Taylor and Francis, London, 2006. 
[8] Tirole, Jean. The Theory of Industrial Organization. Cambridge, MA: The MIT Press, 1995.

[9] Ke, Y., Wang, S. Q., Chan, A. P. C., and Cheung, E., Understanding the risks in China's PPP projects: ranking of their probability and consequence. Engineering, Construction and Architectural Management, 18(5), pp. 481496, 2011.

[10] Xu, Y., Yeung, J. F. Y., Chan, A. P. C., Chan, D. W. M., Wang, S. Q., and Ke, Y., Developing a risk assessment model for PPP projects in China-A fuzzy synthetic evaluation approach. Automation in Construction, 19(7), pp. 929-943, 2010.

[11] Ke, Y., Wang, S. Q., Chan, A. P. C., and Lam, P. T. I., Preferred risk allocation in China's public-private partnership (PPP) projects. International Journal of Project Management, 28(5), pp. 482-492, 2010.

[12] Choi, J. H., Chung, J., and Lee, D. J., Risk perception analysis: Participation in China's water PPP market. International journal of project management, 28(6), pp. 580-592, 2010.

[13] Guasch, J. L., Laffont, J. J., and Straub, S., Renegotiation of concession contracts in Latin America: Evidence from the water and transport sectors. International Journal of Industrial Organization, 26(2), pp. 421-442, 2008.

[14] Grimsey, D., and Lewis, M. K. Public private partnerships: the worldwide revolution in infrastructure provision and project finance. Cheltenham [u.a.]: Elgar, 2007.

[15] Irwin, T., Klein, M., Perry, G. E., and Thobani, M. Dealing with Public Risk in Private Infrastructure-An Overview. Worldbank Publications, 1997.

[16] Shirley, M., and Menard, C., Cities awash: a synthesis of the country cases. Thirsting for efficiency: the economics and politics of urban water system reform, pp. 1-42, 2002.

[17] Bing, L., Akintoye, A., Edwards, P. J., and Hardcastle, C. The allocation of risk in PPP/PFI construction projects in the UK. International Journal of Project Management, 23(1), pp. 25-35, 2005.

[18] Shen, L. Y., Platten, A., and Deng, X., Role of public private partnerships to manage risks in public sector projects in Hong Kong. International journal of Project management, 24(7), pp. 587-594, 2006.

[19] Abrahamson, M., Contractual risks in tunnelling: how they should be shared. Tunnels and Tunnelling, pp. 587-598, 1973.

[20] Posner, R. A., and Rosenfield, A. M., Impossibility and related doctrines in contract law: An economic analysis. The Journal of Legal Studies, 6(1), pp. 83-118, 1977.

[21] Triantis, G. G., Contractual Allocations of Unknown Risks: A Critique of the Doctrine of Commercial Impracticability. The University of Toronto Law Journal, 42(4), pp. 450-483, 1992.

[22] Flanagan, R., and Norman, G. Risk management and construction. Blackwell Scientific Oxford, 1993.

[23] Ting, S., Chen, C., and Bartholomew, D., An integrated study of entrepreneur's opportunism. Journal of Business and Industrial Marketing, 22(5), pp. 322-335, 2007. 
[24] Muller, R., and Turner, R., The impact of principal-agent relationship and contract type on communication between project owner and manager. International Journal of Project Management, 23(5), pp. 398-403, 2005.

[25] Grossman, S. J., and Hart, O. D., The costs and benefits of ownership: A theory of vertical and lateral integration. The Journal of Political Economy, pp. 691-719, 1986.

[26] Alchian, A. A., and Demsetz, H., Production, information costs, and economic organization. The American Economic Review, 62(5), pp. 777795, 1972.

[27] Iossa, E., Spagnolo, G., and Vellez, M., Contract Design in Public-Private Partnerships. Worldbank Publications, 2007.

[28] Hart, O., Incomplete Contracts and Public Ownership: Remarks, and an Application to Public Private Partnerships. The Economic Journal, 113(486), pp. 69-76, 2003.

[29] Laffont, J.-J., and Martimort, D., The theory of incentives: the principal agent model. Princeton [u.a.]: Princeton Univ. Press, 2002.

[30] Klein, M., Bidding for concessions: the impact of contract design. Worldbank Publications, 1998.

[31] Barnes, M., How to allocate risks in construction contracts. International Journal of Project Management, 1(1), pp. 24-28, 1983.

[32] Hölmstrom, B., Moral hazard and observability. The Bell Journal of Economics, pp. 74-91, 1979.

[33] Arndt, R. Getting a fair deal: Efficient Allocation in Private Provision of Infrastructure, The University of Melburne. PhD Dissertation, 2000. 